\title{
Epidemiology and Management of Ectopic Pregnancy in Alex Ekwueme Federal University Teaching Hospital, Abakaliki, Southeast, Nigeria
}

\author{
Bridget Nkiruka Uche-Nwidagu, Vitus Okwuchukwu Obi, Johnbosco Ifunanya Nwafor*, \\ Assumpta Nnenna Nweke, Chinwe Wendy Oliobi, Malachy Chizoba Onyema, \\ Paschal Chijioke Okoye
}

Department of Obstetrics and Gynaecology, Alex Ekwueme Federal University Teaching Hospital, Abakaliki, Nigeria Email: ^nwa forjohnbosco97@gmail.com

How to cite this paper: Uche-Nwidagu, B.N., Obi, V.O., Nwafor, J.I., Nweke, A.N., Oliobi, C.W., Onyema, M.C. and Okoye, P.C. (2019) Epidemiology and Management of Ectopic Pregnancy in Alex Ekwueme Federal University Teaching Hospital, Abakaliki, Southeast, Nigeria. Open Journal of Obstetrics and Gynecology, 9, 1202-1211. https://doi.org/10.4236/ojog.2019.98117

Received: July 20, 2019

Accepted: August 25, 2019

Published: August 28, 2019

Copyright (๑) 2019 by author(s) and Scientific Research Publishing Inc. This work is licensed under the Creative Commons Attribution International License (CC BY 4.0).

http://creativecommons.org/licenses/by/4.0/

\begin{abstract}
Background: Ectopic pregnancy is a common cause of maternal morbidity and mortality in the $1^{\text {st }}$ trimester of pregnancy; without timely diagnosis and intervention, ruptured ectopic pregnancy can become a life threatening condition. Objective: This study aims to give baseline indices on the incidence, clinical presentation, risk factors and the management of cases of ectopic pregnancy that presented in Alex Ekwueme Federal University Teaching Hospital, Abakaliki over a 5-year period. Materials and Method: This is a 5-year retrospective study of patients who were diagnosed with ectopic pregnancy between January $1^{\text {st }} 2012$ and December $31^{\text {st }} 2016$. The statistical analysis was done using SPSS version 22. Result: During the study period, there were 11,932 deliveries while 7725 Gynaecology patients were admitted. Over the same period there were 156 patients diagnosed and managed for ectopic pregnancy, accounting for $1.31 \%$ of all deliveries and $2.0 \%$ of all Gynaecological admissions. The modal age group was 26 - 30 years 68 (43.6\%), 122 (78.2\%) were married, while $34(21.7 \%)$ were single. Nulliparous were 41 (26.3\%) and primiparous were $33(21.2 \%)$. The commonest presenting complaints were lower abdominal pain and amenorrhea, and the commonest identified risk factor was previous pelvic inflammatory disease. Most of the cases were ruptured prior to presentation and partial salpingectomy was the management in all tubal pregnancy while two cases were unruptured and had salpingostomy and another case was abdominal pregnancy and had exploratory laparotomy only. Out of 156 women that presented with ectopic pregnancy, 8 (5.1\%) died before surgery could be done due to late presentation. Fifty-seven women presented in a state of shock and 9 (5.8\%) of the cases
\end{abstract}


were complicated with acute renal failure. Conclusion: Ruptured ectopic pregnancy is a major cause of maternal morbidity and early pregnancy loss. Late presentation is a common feature in our environment; hence widespread advocacy on case identification and early presentation is urgently needed.

\section{Keywords}

Epidemiology, Management, Ectopic Pregnancy, Abakaliki

\section{Introduction}

Ectopic pregnancy is defined as implantation of a conceptus outside the normal uterine cavity [1] [2] [3] [4] [5]. It is one of the leading causes of maternal morbidity and mortality especially in the tropics where late booking is very common [2]. Though globally, the morbidity and mortality associated with ectopic pregnancy have decreased dramatically, mainly because of earlier diagnosis with ultrasound and $\beta$-hCG levels and subsequent treatment before it ruptures. Nevertheless, it is the leading cause of pregnancy related death in the first trimester and accounts for $4 \%-10 \%$ of all pregnancy related deaths globally [2].

The incidence of ectopic pregnancy varies among and within countries [3]. The incidence is related to liberal sexual practices and prevalence of pelvic inflammatory diseases [3] [5]. The perceived increase in the incidence of ectopic pregnancy may be due to a larger number of the cases in the population or a result of the improved sensitivity of the diagnostic test for ectopic pregnancy. In the past, a significant number of ectopic pregnancies may have been resolved spontaneously without being detected, which is less likely in modern clinical practice [6]. Ectopic pregnancy occurs in approximately $1.5 \%-2.0 \%$ of all pregnancies. The incidence has increased from 4.5 per 1000 in 1970 to 19.7 per 1000 in 1992 [2]. The reported annual incidence rates vary between 100 and 175 per 100,000 women aged 15 - 44 [6]. The incidence in the UK has increased from 9.6 per 1000 pregnancies in 1991-1993 to 11.1 per 1000 pregnancies in 2003-2005 [1] [6]. The incidence of ectopic pregnancy in developing countries is rather high as compared to developed countries. In Jamaica, the incidence is 1 in 28 deliveries, 1 in 21 deliveries in South Korea and 1 in 24.4 deliveries in Ghana. In the United States of America, the incidence is 1 in 241 deliveries to 1 in 280 deliveries while in Nigeria, the rate of 1 in 20 pregnancies has been reported in the southern cities compared to 1 in 50 in the Northern cities of Nigeria [3] [5]. The rate in southeast Nigeria was 1 in 90 deliveries and incidence of 11.1 per 1000 pregnancies [7].

Several factors have been shown to increase the risk of ectopic pregnancy. These risk factors share a common mechanism of action viz interference with the ciliary functions of the fallopian tube [6] [7]. It has been observed that pelvic inflammatory disease is the most common risk factor for ectopic pregnancy and 
early treatment of the disease does not necessarily prevent tubal damage [7] [8]. The other reported aetiological factors including previous ectopic pregnancy, endometriosis, previous tubal surgery, infertility treatment, previous caesarean sections, tubal spasm, congenital defects of the fallopian tube, psychological and emotional factors have also been implicated [8]. Other factors associated with an increased risk of ectopic pregnancy include cigarette smoking [6].

No specific symptoms or signs are pathognomonic for ectopic pregnancy [8]-[25]. It has been described as the great masquerader [9]. In the diagnosis of ectopic pregnancy, a high index of suspicion is needed especially in a young sexually active woman presenting with amenorrhea, abdominal pain and vaginal bleeding. In the confirmation of ectopic pregnancy, pelvic ultrasonography is the goal standard for diagnosis since it is non-invasive and relatively cheap and readily available; laparoscopy can be used for diagnosis and treatment especially for small unruptured cases, culdocentesis and abdominal paracentesis still have a role to play especially in resource poor setting with no ultrasound, skilled operators or electricity. Recently the "shock index" has been shown to play an essential role in the diagnosis of ruptured ectopic pregnancy [9].

Laboratory diagnostic test include serial human chorionic gonadotrophin values which can be measured in serum starting from $8-12$ days after fertilization and doubles every two days in normal pregnancy, the B-submit of HCG is positive in $100 \%$ of ectopic pregnancy whereas the urine pregnancy test for $\beta$-hCG is positive in only $50 \%$ of ectopic pregnancy, the progesterone assay is < $15 \mathrm{ng} / \mathrm{ml}$ in ectopic pregnancy [9]. Various values of Human Chorionic Gonadotrophin had been used as "Discriminating Zone" in relation to ultrasound scan and estimated gestational age [9]. Endometrial histology which may show decidual reaction without evidence of chorionic villi or Arias-Stella reactions may also be used in the diagnosis of ectopic pregnancy [9] [10].

In the majority of cases, especially in resource poor setting like ours, surgery is the mode of treatment. The surgical treatment may either be an open surgery or laparoscopic depending on the surgeon's skill, availability of equipment and clinical state of the patient. The management of ectopic pregnancy has been revolutionized over the past few decades. This has resulted in emergence of several non-surgical options to what had once thought to be a solely surgical treatable condition. An earlier diagnosis can be made with transvaginal ultrasound and quantitative serum $\beta$-hCG. This increases the chances of success of medical treatment and minimizes its morbidity, mortality and financial burden [11]-[20]. For ruptured ectopic pregnancy, salpingectomy is the available treatment modality [21] [22] [23] [24] [25] this management option is invasive but it is life saving and effective. Intra operative blood salvage and auto transfusion is a simple effective and safe method of blood replacement in the surgical management of ruptured ectopic pregnancy, especially in resource poor settings [11]. In unruptured ectopic pregnancy in adequately selected and well-motivated patients, conservative surgery can be done [22]. Medical treatment can also be employed using systemic or ultrasound guided local injection of methotrexate, ac- 
tinomycin D, potassium chloride, or mifepristone [23]. The chance of intrauterine pregnancy in subsequent pregnancies is $40 \%$ after salpingectomy, $60 \%$ after conservative tubal surgery, $87 \%$ after medical treatment. The recurrent ectopic pregnancy rates after radical and conservative management are similar 10\% $20 \%$ [24] [25]. Therefore there is a need for evaluation of outcomes of women managed for ectopic pregnancy in our hospital. The aim of this study was to determine the incidence, clinical presentation, risk factors and the management of cases of ectopic pregnancy that presented in Alex Ekwueme Federal University Teaching Hospital, Abakaliki.

\section{Materials and Method}

This was a 5 year retrospective study of patients who were diagnosed of ectopic pregnancy between $1^{\text {st }}$ January 2012 to $31^{\text {st }}$ June 2016 at the Obstetrics and Gynaecology department of the Alex Ekwueme Federal University Teaching Hospital, Abakaliki. The hospital is a tertiary hospital located at the centre of the state capital of Ebonyi State; the department runs gynecological clinics, gynaecological emergency, antenatal, intrapartum, and postnatal services. It is also a referral centre for the surrounding maternities and hospitals and also receives referral from surrounding states; Cross Rivers, Enugu, and Benue states. Ebonyi state is one of five states in the south eastern geopolitical zones in Nigeria. The state consists of thirteen Local Government Areas, with each Local Government having a General Hospital and a few missionary hospitals. It has an estimated population of 2.1 million people and lie at between 7"3" $\mathrm{N}$ longitude and 5"4" $\mathrm{E}$ latitude with a land mass approximately 5932 square kilometres.

Ethical approval was obtained from the research and ethics committee of the hospital. A proforma was used to collect information on the Biodata, clinical symptoms and signs, risk factor, clinical state at presentation, the type of ectopic and site of the ectopic, the surgeon and type of surgery and the need for blood transfusion services. Data analysis was done using IBM SPSS Statistics 20.

\section{Result}

Over the study period, there were a total of 11,932 deliveries, 7725 gynaecological admissions and 156 ectopic pregnancies. This gives an incidence of $1.31 \%$ of total deliveries and $2.0 \%$ of gynecological admissions. The mean age was 28 years, the range is between 17 years and 46 years, modal age group 53 (33.9\%) was 26 - 30 years. Majority 122 (78.2\%) were married and most had secondary school as their highest level of education 55 (35.3\%). The incidence is more among women with low parity as $41(26.3 \%)$ are nulliparous (Table 1 ).

Table 2 represents the clinical features of patients with ectopic pregnancy in the study. This shows that nearly all the patients 146 (93.6\%) had lower abdominal pain at presentation. Other presenting complaints include amenorrhea 114 (73.1\%), 72 (46.2\%) had bleeding per vaginam while fainting spell/collapse was seen in $20(12.8 \%)$ of all the cases. The commonest identified risk factors 
Table 1. Socio-demographic characteristics of patients.

\begin{tabular}{|c|c|c|}
\hline Age in years & No of patients & Percentages (\%) \\
\hline $16-20$ & 13 & 8.3 \\
\hline $21-25$ & 43 & 27.6 \\
\hline $26-30$ & 68 & 43.6 \\
\hline $31-35$ & 22 & 14.1 \\
\hline $36-40$ & 7 & 4.5 \\
\hline $41-50$ & 3 & 1.9 \\
\hline Total & 156 & 100.0 \\
\hline \multicolumn{3}{|c|}{ Educational Level } \\
\hline None & 8 & 5.1 \\
\hline Primary & 42 & 26.9 \\
\hline Secondary & 55 & 35.3 \\
\hline Tertiary & 51 & 32.7 \\
\hline Total & 156 & 100 \\
\hline \multicolumn{3}{|l|}{ Marital Status } \\
\hline Married & 122 & 78.2 \\
\hline Single & 34 & 21.8 \\
\hline Total & 156 & 100.0 \\
\hline \multicolumn{3}{|l|}{ Parity } \\
\hline 0 & 41 & 26.3 \\
\hline 1 & 33 & 21.2 \\
\hline 2 & 32 & 20.5 \\
\hline 3 & 27 & 17.3 \\
\hline 4 & 8 & 5.1 \\
\hline$>5$ & 15 & 9.6 \\
\hline Total & 156 & 100.0 \\
\hline
\end{tabular}

include previous poorly treated sexually transmitted disease/pelvic inflammatory disease 70 (44.9\%), previous termination of pregnancy 23 (14.7\%), while 25 (16.0\%) had multiple sexual partners. Those that had previous ectopic pregnancies were $4(2.6 \%)$ while $2(1.3 \%)$ had puerperal sepsis as a risk factor. There was no identified risk factor in $43(27.6 \%)$ of the patients while $1(0.0 .6 \%)$ had a history of infertility. At presentation 57 (36.5\%) were in shock, while 99 (63.5\%) were clinically stable (Table 2).

Those that had tubal ectopic were 153 (98.1\%), 1 (0.6\%) had abdominal pregnancy while $2(1.3 \%)$ had ovarian pregnancy. Patients who presented with ruptured ectopic pregnancy 152 (97.4\%) while $1(0.6 \%)$ was unruptured tubal ectopic and $1(0.6 \%)$ was abdominal pregnancy. The ectopic pregnancy occurred on the right in 83 (53.2\%) while the left side contributed the remaining 70 (44.9\%) (Table 3). Blood transfusion was required in the management of 113 (72.4\%) of the patients, while the other did not require blood transfusion services. 
Table 2. Clinical features of the patients.

\begin{tabular}{ccc}
\hline Presenting complaints & No of patients & Percentages \\
\hline Abdominal pain & 146 & 93.6 \\
Amenorrhoea & 114 & 73.1 \\
Bleeding per vaginam & 72 & 46.2 \\
Fainting spell & 20 & 12.8 \\
\hline Identifiable risk factors & & \\
\hline Poorly treated STI/PID & 70 & 44.9 \\
Multiple sexual partners & 25 & 16.2 \\
Previous termination of pregnancy & 23 & 14.7 \\
History of infertility & 1 & 0.6 \\
Previous history of ectopic & 4 & 2.6 \\
History of puerperal sepsis & 2 & 1.3 \\
No identified risk factor & 43 & 27.6 \\
\hline Clinical state at presentation & 156 & 63.5 \\
\hline Stable & 99 & 36.5 \\
Shock & 57 & 100.0 \\
\hline Total & & \\
\hline
\end{tabular}

Senior registrars were the surgeons in $111(71.2 \%)$ of the cases while consultants carried out 38 (24.4\%) of the cases, registrars carried out 7 (4.5\%) of the cases. One hundred and thirty-three (85.3\%) were discharged within 8 days of admission while 23 (14.7\%) went home after 8 days (Table 3).

Complications suffered by women with ectopic pregnancy are shown in Table 4. Out of 156 women that presented with ectopic pregnancy, 8 (5.1\%) died before surgery could be done due to late presentation. Fifty-seven women presented in a state of shock and $9(5.8 \%)$ of the cases were complicated with acute renal failure.

\section{Discussion}

Ectopic pregnancy is a common cause of maternal morbidity and mortality in the first trimester of pregnancy. The incidence of ectopic pregnancy in this study was $1.31 \%$ of all deliveries, this is consistent with the $1.3 \%-1.5 \%$ reported in similar studies [12] [14] [17] [22] but is much lower than $1.8 \%-4.26 \%$ found in other studies both in Nigeria and outside Nigeria [3] [6]. This is however, higher than $0.6 \%$ of total births in Pakistan [14] or $0.9 \%$ of total deliveries in another study in Nnewi [7]. This could be because of the duration of the study, the locality and/or patients characteristics.

The highest incidence was amongst patient aged $26-30$, this is consistent with findings in other studies [7] [8] [9] [12] [13] [14]. This represents women in their reproductive age and the peak of sexual activities [17]. Poor contraceptive 
Table 3. Treatment modalities received by the participants.

\begin{tabular}{|c|c|c|}
\hline Site of ectopic & No of patients & Percentages \\
\hline Right & 83 & 53.2 \\
\hline Left & 70 & 44.9 \\
\hline Abdominal & 1 & 1.3 \\
\hline Ovary & 2 & 1.3 \\
\hline Total & 156 & 100 \\
\hline \multicolumn{3}{|l|}{ Need for blood transfusion } \\
\hline Yes & 113 & 72.4 \\
\hline No & 43 & 27.4 \\
\hline Total & 156 & 100.0 \\
\hline \multicolumn{3}{|l|}{ Surgeons } \\
\hline Consultants & 38 & 24.4 \\
\hline Senior Registrar & 111 & 71.2 \\
\hline Registrar & 7 & 4.5 \\
\hline \multicolumn{3}{|l|}{ Type of surgery } \\
\hline Salpingectomy & 151 & 96.8 \\
\hline Salpingo-oophorectomy & 1 & 0.6 \\
\hline Exploratory laparotomy only & 3 & 1.9 \\
\hline Salpingostomy & 1 & 0.6 \\
\hline Total & 156 & 100 \\
\hline \multicolumn{3}{|l|}{ Duration of Hospital Stay } \\
\hline$<8$ days & 133 & 85.3 \\
\hline$>8$ days & 23 & 14.7 \\
\hline Total & 156 & 100 \\
\hline
\end{tabular}

Table 4. Complications of ectopic pregnancies among women in this study.

\begin{tabular}{ccc}
\hline Complications & No of patients & Percentage \\
\hline Shock & 57 & 36.5 \\
Acute renal failure & 9 & 5.8 \\
Death & 8 & 5.1 \\
\hline
\end{tabular}

usage and increased risk of sexually transmitted infections are common among this age group [23].

Majority of the women had secondary education only and this is similar to the study done in Nnewi [17]. This is a reflection of the socio-economic situation of the area and poor contraceptive usage by this group.

Nearly half of the patients were either in their first or second pregnancy, this is consistent with most findings in Nigeria [12] [13] [17] [22]. This may be ex- 
plained from the fact that multiple sexual partners and sexually transmitted infection and pelvic infections may predate most of these pregnancies [17].

Lower abdominal pain was the commonest complaint at presentation this is often due to rupture of the tubal ectopic as a result of late presentation. Other clinical features are absence of menses/amenorrhoea, bleeding per vaginam, and fainting spell, these are complications that follow ruptured ectopic and these findings are in line with other studies [8] [9] [12]-[23].

The commonest identified risk factors were poor treated sexually transmitted infection $44.9 \%$, multiple sex partners, and then previous history of abortions. Four patients had a previous history of ectopic pregnancy, while $27.6 \%$ had no identifiable risk factors. This is similar to the study done in Pakistan [14] and India [20], but not consisted with other findings were previous induced abortion was the commonest identified risk factor [8] [9] [12] [13]. This may be because of non-disclosure as most patients would willingly choose to hide such information because of societal perception of people who have had an induced abortion. One patient had a history of fertility treatment showing that it is a risk factor to ectopic pregnancy though rare [10] [11].

Despite late presentation to the hospital, most of the patients presented in a fairly stable clinical state. Blood transfusion was required in the management of $72.4 \%$ of these patients as most of them presented following rupture of the ectopic. This underlines the late presentation of these patients. In a similar study in Niger Delta, most of the patients were anaemic and required blood transfusion [13], autologous blood transfusion was not done for any of the patients because of their late presentation and the fact that most of the blood evacuated did not meet the criteria.

The tubal ectopic was commoner on the right than on the left, this may be as a result of inflammation of the appendix [24], this finding consists with other studies [9] [14].

Senior registrars were the surgeons in $71.2 \%$ of the cases while consultants carried out $24.4 \%$ of the cases, this is similar to the finding in Kano [25]. This is because most cases present as emergency during odd hours and require prompt intervention to relieve the morbidity and prevent maternal mortality. Most of the patients were discharged within 8 days on admission. Fortunately there were no maternal deaths during the study, probably due to the prompt intervention given to all the patient at presentation.

Most of the patient with tubal ectopic presented with ruptured tubal ectopic pregnancy except $0.6 \%$ who presented with unruptured tubal ectopic, this is similar to the finding in Nnewi, Niger Delta and Sokoto [12] [13] [17]. These towns have similar patient characteristics to those found in this study. In this study as in most reports in sub Saharan Africa, ectopic gestation was treated mostly by laparotomy and salpingectomy. This is due mainly to late presentation to the hospital as most the patients in this series presented after the tubal ectopic had ruptured [12]-[22] [25].

This study has some limitation. The incidence of repeat ectopic pregnancy 
and intrauterine pregnancies could not be assessed because most of the women were lost to follow-up. The authors recommend a prospective study to assess the outcomes of subsequent pregnancies among women with previous ectopic pregnancies in our locality.

\section{Conclusion}

Ectopic pregnancy is still a major gynaecological emergency with its attendant maternal morbidity and mortality. It is a public health issue as the risk factors include poorly treated sexually transmitted infections and pelvic inflammatory diseases and multiple sexual partners. Poor health seeking behaviour is apparent as most of the patients presented late after rupture of the ectopic pregnancy. Ignorance, poverty and illiteracy compound the problem. Health education, safer sex practices, improved infrastructures and manpower development are urgently required to reduce this menace.

\section{Conflicts of Interest}

The authors declare no conflicts of interest regarding the publication of this paper.

\section{References}

[1] Horne, A. (2011) Problems of Early Pregnancy. In: Ash, M. and Dobbs, S., Eds., Gynecology by Ten Teachers, 19th Edition, Hodder Arnold, London, 94-98.

[2] Ann-Marie, S. and Samantha, M.D. (2011) Early Pregnancy Risks. In: Alan, H.D., Lauren, N., Neri, L. and Ashley, S.R., Eds., Current Diagnosis and Treatment in Obstetrics and Gynecology, 11th Edition, The McGraw-Hill Companies, USA, 234-249.

[3] Pam, I.C. and Otubu, J.A.M. (2005) Ectopic Pregnancy. In: Agboola, A., Ed., Textbook of Obstetrics and Gynaecology for Medical Students, 2nd Edition, Heinemann Education Books (Nig) Plc, Nigeria, 101-105.

[4] Saxena, R. (2010) Ectopic Pregnancy. In: Saxena, R., Ed., Bedside Obstetrics and Gyneacology, Jaypee Brothers Medical Publishers LTD., New Delhi, 486-501. https://doi.org/10.5005/jp/books/11189_25

[5] Kwawukume, E.Y., Idrisa, A. and Ekele, B.A. (2015) Ectopic Pregnancy. In: Kwawukume, E.Y., Emuveyan, E.E., Ekele, B.A. and Danso, K.A., Eds., Comprehensive Obstetric for the Tropics, Asante and Hittscher Printing Press, Ghana, 282-288.

[6] Jurkovic, D. (2012) Ecotpic Pregnancy. In: Edmond, D.K., Ed., Dewhurst's Textbook of Obstetrics and Gynecology, 8th Edition, John Willey and Sons Ltd., Hoboken, 76-87. https://doi.org/10.1002/9781119979449.ch9

[7] Igwegbe, A.O., Eleje, G.U. and Okpala, B.C. (2013) An Appraisial of the Management of Ectopic Pregnancy in a Nigerian Tertiary Hospital. Annals of Medical and Health Science Research, 3, 166-170. https://doi.org/10.4103/2141-9248.113655

[8] Akbar, N., Shami, N., Anwar, S. and Asif, S. (2002) Evaluation of Predisposing Factors of Tubal Pregnancy in Multigravidas versus Primigravidas. Journal of Surgery Pakistan Institute of Medical Sciences, 25, 20-23.

[9] Lawani, O.L., Anozie, O.B. and Ezeonu, P.O. (2013) Ectopic Pregnancy; a Necological-Threatening Gynecological Emergency. International Journal of Women's Health, 5, 515-521. 
[10] Eze, J.N., Obuna, J.A. and Ejikeme, B.N. (2012) Bilateral Tubal Ectopic Pregnancies: A Report of Two Cases. Annals of African Medicine, 11, 112-115. https://doi.org/10.4103/1596-3519.93535

[11] Nwali, M.I., Ejikeme, B.N., Onyebuchi, A.K., Onoh, R.C. and Edegbe, F.O. (2014) Bilateral Tubal Ectopic Gestation: A Case Report. Annals of Nigerian Medicine, 8, 45-47. https://doi.org/10.4103/0331-3131.141030

[12] Panti, A., Ikechukwu, N.E., Omokanye, O.I., Ahmed, Y., Egondu, S.C. and Tanko, B.A. (2012) Ectopic Pregnancy at Usman Danfodiyo University Teaching Hospital, Sokoto. A Ten Year Review. Annals of Nigerian Medicine, 2, 87-91. https://doi.org/10.4103/0331-3131.108128

[13] Igberase, G.O., Ebeigbe, P.N., Igbekoyi, O.F. and Ajufoh, B.I. (2005) Ectopic Pregnancy: An 11 Year Review in a Tertiary Centre in Niger Delta. Tropical Doctor, 35, 175-177. https://doi.org/10.1258/0049475054620888

[14] Khaleeque, F., Siddiqu, R.I. and Jafarey, S.N. (2001) Ectopic Pregnancies: A Three Year Study. Journal of Pakistan Medical Association, 51, 240.

[15] Yeasmin, S., Uddin, M.J. and Hasan, E. (2014) A Clinical Study of Ectopic Pregnancies in a Tertiary Care Hospital of Chittagong, Bangladeh. Chattagram Maa-O-Shishu Hospital Medical College Journal, 13, 1-4. https://doi.org/10.3329/cmoshmcj.v13i3.20993

[16] Shaikh, N.B., Shabnam, S. and Farhana, S. (2014) A Clinical Study of Ectopic Pregnancy. Journal of Ayub Medical College Abbottabad, 26, 178-181.

[17] Udigwe, G.O., Umeononihu, O.S. and Miachin, I.I. (2010) Ectopic Pregnancy; A 5 Year Review of Cases at Nnamdi Azikiwe University Teaching Hospital (NAUTH), Nnewi. Nigerian Medical Journal, 51, 160-163.

[18] Mignin, L. (2007) Interventions for Tubal Ectopic Pregnancy. RHL Commentary. The WHO Reproductive Health Library, World Health Organization, Geneva.

[19] Muftl, S.M.S., Shagutta, R.M.S., Wasigs, M.S. and Khalida, D.G.O. (2012) Ectopic Pregnancy: An Analysis of 114 Cases. JK-Practitioner, 17, 20-23.

[20] Prasanna, B., Jhans, C.B., Swathi, K. and Shaik, M.V. (2016) A Study on Risk Factors and Clinical Presentation of Ectopic Pregnancy in Women Attending a Tertiary care Centre. International Archives of Integrated Medicine, 3, 90-96.

[21] Wakankar, R. and Kshama, K. (2015) Ectopic Pregnancy-A Rising Trend. International Journal of Scientific Study, 5, 18-22.

[22] Ikeme, A.C.C. and Ezegwui, H.U. (2005) Morbidity and Mortality Following Tubal Ectopic Pregnancy in Enugu, Nigeria. Journal of Obstetrics and Gynaecology, 25, 596-598. https://doi.org/10.1080/01443610500239552

[23] Marion, L. and Meeks, G.R. (2012) Ectopic Pregnancy: History, Incidence, Epidemiology, and Risk Factors. Clinical Obstetrics and Gynecology, 55, 376-386. https://doi.org/10.1097/GRF.0b013e3182516d7b

[24] Cunningham, F.G., Leveno, K.J., Bloom, S.L., Hauth, J.C. and Rouse, D.J. (2010) Ectopic Pregnancy. In: Williams Obstetrics, 23rd Edition, McGraw Hill, New York, 238-256.

[25] Yakasai, I.A., Abdullahi, J. and Abubakar, I.S. (2012) Management of Ectopic Pregnancy in Aminu Kano Teaching Hospital Kano Nigeria: A 3-Year Review. Global Advanced Research Journal of Medicine and Medical Sciences, 1, 181-185. 